\title{
Ticlopidine and aspirin interactions
}

The success of coronary angioplasty depends largely on the efficacy of the antithrombotic regimen that is used to prevent acute or subacute occlusions without causing bleeding. ${ }^{12}$ Abrasion of the endothelium and plaque fissuring, which are unavoidable during successful angioplasty, expose the highly thrombogenic subendothelial components and the lipid-rich core of the plaque to coagulation factors. Thrombin promotes deposition of fibrin strands that activate the coagulation cascade and the platelets.

The optimal antithrombotic regimen in angioplasty is not yet defined, ${ }^{3}$ and numerous trials have been undertaken to compare the impact of the various antithrombotic or antiplatelet drugs that interfere at various sites in the coagulation cascade.

\section{Aspirin: the oldest antiplatelet drug}

Despite the discovery of new antiplatelet drugs, aspirin (acetylsalicylic acid) remains one of the main agents used to prevent acute and subacute occlusions after coronary dilatation procedures, ${ }^{3}$ and it has the most favourable cost-effect and side-effect balance. Aspirin has therapeutic antiplatelet effects at low doses ${ }^{4}$ : in fact single oral dose of $30-50 \mathrm{mg}$ a day given for 7-10 days completely suppressed thromboxane biosynthesis. At doses of $300 \mathrm{mg}$ a day or more, aspirin was less effective against platelet aggregation but seemed to have a fibrinolytic effect. ${ }^{4}$ Aspirin was of benefit in myocardial infarction, in unstable angina, and in coronary angioplasty ${ }^{3}$ but it is a relatively weak antiplatelet agent that did not completely protect patients from acute and subacute thrombosis. ${ }^{1-3}$ Moreover in more aggressive debulking techniques such as in implantation of multiple stents or in rotational or directional atherectomy during which the vessel wall is extensively denuded of endothelium, the effect of aspirin and heparin need to be potentiated to minimise the risks of occlusion. ${ }^{56}$ Nonetheless Colombo $e t a l^{7}$ in an intravascular ultrasound (IVUS) guided study reported that in a cohort of patients treated with aspirin and heparin, the risk of occlusion was mainly attributable to inappropriate coverage of the lesion by the stent. Hence the suggestion that the doctor might be more thrombogenic than the stent. $^{8}$

\section{Oral anticoagulation regimen}

Intensive anticoagulation can cause bleeding and vascular complications. The combined use of aspirin and coumadin was associated with a high bleeding complication rate. ${ }^{5}$ Despite this untoward effect, an anticoagulation regimen is still the only one approved by the Food and Drug Administration. Schömig et al in a randomised trial performed in patients who underwent stent implantation found that the incidence of both cardiac and haemorrhagic events was significantly lower with a combination of aspirin

\footnotetext{
Glossary

STARS = stent antithrombotic regimen study

MUSIC = multicentric stent intracoronary study

WEST II = Western European stent trial

TASTE = ticlopidine aspirin stent evaluation study

MUST $=$ multicentre stent ticlopidine study
}

and ticlopidine than with the coumadin and aspirin regimen. ${ }^{6}$

\section{The rationale of combining ticlopidine and aspirin}

The rationale of combining these two antiplatelet drugs lies in taking advantage of their different mechanisms of action $^{49}$ which may potentiate each other. Aspirin and ticlopidine both have a longlasting antithrombotic effect but they differ in several mechanisms of action. Aspirin ${ }^{4}$ by acetylating one hydroxyl group, inactivates the cyclooxygenase catalytic activity of prostaglandin $\mathrm{G} / \mathrm{H}$ synthase and hence reduces the production of thromboxane $A_{2}$, prostaglandin $E_{2}$, and prostacyclin. In addition the aspirin effect is long lasting. It produces permanent cyclooxygenase inhibition because platelets, lacking the biosynthetic machinery, cannot synthesise new proteins. ${ }^{4}$

Ticlopidine, however, inhibits the three mechanisms of platelet activation: it reduces ADP-induced platelet aggregation and serotonin release from platelets and interferes with fibrinogen receptors on the platelet membrane. ${ }^{9}$ The expression of fibrinogen receptor (glycoprotein IIb/IIIa) on the surface of platelets but not the fibrinogen plasma concentration is an independent predictor of subacute stent thrombosis. ${ }^{10}$ Thus the reduction of fibrinogen receptors on platelets might be a point in favour of the use of ticlopidine. On the other hand, the antiplatelet effect of ticlopidine only reaches its full effect 3-5 days after the oral dose of $250 \mathrm{mg}$ twice a day. ${ }^{11}$ This suggests that ticlopidine can be used only in the case of planned percutaneous transluminal coronary angioplasty (PTCA). In fact measurements of the activation of coagulation performed in the distal coronary segments in patients undergoing various dilatation procedures ${ }^{11}$ such as conventional PTCA, stent implantation, or rotational ablation indicated that pretreatment with ticlopidine for 72 hours $(250$ $\mathrm{mg}$ twice a day) combined with aspirin reduced markers of thrombin generation and platelet activation to normal laboratory values. Such treatment did not significantly change the activation of coagulation between basal venous and coronary ostium samples as compared with the values obtained at the coronary ostium and in the distal dilated coronary artery during the procedures, irrespective of the presence of unstable angina or the use of a Rotablator. The clinical use of the ticlopidine analogue clopidogrel, which has the advantage of a more rapid effect (now under investigation), may overcome this problem.

\section{Role of serotonin released by platelets}

Another potential advantage of the use of ticlopidine in angioplasty may be the effect of the drug in reducing platelet serotonin release. It has been suggested that serotonin released from locally activated platelets contributes to post-PTCA coronary vasoconstriction. ${ }^{12}$ However, despite the significant reduction in intracoronary serotonin release obtained by 72 hours ticlopidine pretreatment in our experiments, we found no difference in vasoconstriction in patients treated with ticlopidine and those who were not. ${ }^{11}$ Therefore the beneficial effect of the use of ticlopidine may not imply the vasoconstriction. As we have previously demonstrated 13 "elastic recoil" occurring 15-30 minutes after coronary dilatation can be coun- 
teracted by $\alpha$-adrenergic sympathetic receptor antagonists.

\section{Summary}

The risk-benefit balance when aspirin is compared with aspirin combined with ticlopidine is being investigated in several multicentre trials (MUSIC and WEST II versus TASTE, MUST, and STARS respectively)..$^{14}$

Cardiologists follow one of two strategies. Some prefer a more aggressive antiplatelet regimen, disregarding the risk of neutropenia $(0.7 \%)$ because they want to avoid lessening the therapeutic effect of vessel patency obtained with stent implantation. ${ }^{14}$ Others give only aspirin ${ }^{715}$ (a money saving approach) confident that IVUS inspection (an expensive approach) will allow an adequate evaluation of full stent expansion and lesion coverage, ${ }^{15}$ despite a more pronounced activation of the coagulation cascade. ${ }^{61011}$ Our impression so far is that the combination of ticlopidine and aspirin has a more favourable risk-effect balance.

Clinica Medica Generale, LUISA GREGORINI

Università di Milano,

Ospedale Maggiore IRCCS, Italy

Clinique Pasteur,

JEAN MARCO

Unitè de Cardiologie Interventionelle,

Toulouse,

France
1 de Feyter PJ, Van den Brand M, Jaarman GJ, Serruys PW, et al. Acute coronary artery occlusion during and after percutaneous transluminal coronary angioplasty: frequency, prediction, clinical course, management, and follow-up. Circulation 1991;83:927-36.

2 McGarry TF Jr, Gottlieb RS, Morganroth J, et al. The relationship of anticoagulation level and complications after percutaneous transluminal coronary angioplasty. Am Heart $\mathcal{f} 1992 ; 123: 1445-51$.

3 Antiplatelet Trialists' Collaboration. Collaborative overview of randomised trials of antiplatelet therapy II: Maintenance of vascular grafts or arterial patency by antiplatelet therapy. $B M F$ 1994;308:159-68.

4 Patrono C. Aspirin as an antiplatelet drug. NEngl ₹ Med. 1994;330:1287-94.

5 Serruys PW, de Jaegere P, Kiemeneij F, et al. for the Benestent Study Group. A comparison of balloon-expandable-stent implantation with balGroup. A comparison of balloon-expandable-stent implantation with bal-
loon angioplasty in patients with coronary artery disease. $N$ Engl $\mathcal{F} M e d$
1994;331:489-95.

6 Schömig A, Neumann FJ, Kastrati A, et al. A randomized comparison of antiplatelet and anticoagulant therapy after the placement of coronaryartery stents. $N$ Engl $f$ Med 1996;334:1084-9.

7 Colombo A, Hall P, Nakamura S, et al. Intracoronary stenting without anticoagulation accomplished with intravascular ultrasound guidance. Circulation 1995;91:1891-3.

8 Serruys PW, Di Mario C. Who was thrombogenic: the stent or the doctor? Circulation 1995;91:1676-88.

9 McTavish D, Faulds D, Goa KL. Ticlopidine an updated review of its pharmacology and therapeutic use in platelet dependent disorders. Drugs 1990;40:238-59.

10 Neumann F-J, Gawaz M, Schömig A, et al. Prospective evaluation of hemostatic predictors of subacute stent thrombosis after coronary Palmaz-Schatz stenting. $f$ Am Coll Cardiol 1996;27:15-21.

11 Gregorini L, Marco J, Fajadet J, et al. Ticlopidine and acetylsalicylic acid pretreatment reduce coagulation and platelet activation during coronary dilatation procedures. $\mathcal{F} \mathrm{Am}$ Coll Cardiol 1997;28:(in press).

12 Golino P, Piscione F, Benedict CR, et al. Local effect of serotonin released during coronary angioplasty. N Engl f Med 1994;330:523-8.

13 Gregorini L, Fajadet J, Marco J, et al. Coronary vasoconstriction following percutaneous transluminal coronary angioplasty is attenuated by antiadrenergic agents. Circulation 1994;90:985-97.

14 Morice MC, Valeix B, Marco J, et al. Preliminary results of the MUST trial. Major clinical events during the first month. $\mathcal{F}$ Am Coll Cardiol 1996;27 (supplA):731-2, 137A.

15 de Jaegere $P$ for the MUSIC Study Investigators. In hospital and 1-month clinical results of an international study testing the concept of IVUS clinical results of an international study testing the concept of IVUS
guided optimized stent expansion alleviating the need of systemic anticoagulation. $\mathcal{A}$ Am Coll Cardiol 1996;27(supplA):731-5, 137A. 